\title{
An aortic ring: From physiologic reconstruction of the root to a standardized approach for aortic valve repair
}

\author{
Emmanuel Lansac, MD, PhD, ${ }^{\mathrm{a}}$ Isabelle Di Centa, MD, ${ }^{\mathrm{b}}$ Ghassan Sleilaty, MD, ${ }^{\mathrm{b}}$ Eric Arnaud Crozat, MD, ${ }^{\mathrm{c}}$ \\ Olivier Bouchot, MD, PhD, ${ }^{\mathrm{d}}$ Rachid Hacini, MD, ${ }^{\mathrm{e}}$ Dominique Blin, MD, ${ }^{\mathrm{e}}$ Fabien Doguet, MD, PhD, ${ }^{\mathrm{f}}$ \\ Jen-Paul Bessou, MD, PhD, ${ }^{\mathrm{f}}$ Bernard Albat, $\mathrm{MD}, \mathrm{PhD},{ }^{\mathrm{g}}$ Roland De Maria, $\mathrm{MD}, \mathrm{PhD},{ }^{\mathrm{g}}$ \\ Jean-Pierre Villemot, MD, PhD, ${ }^{\mathrm{h}}$ Eric Portocarrero, MD,${ }^{\mathrm{h}}$ Christophe Acar, MD, PhD, ${ }^{\mathrm{i}}$ Didier Chatel, MD, ${ }^{\mathrm{j}}$ \\ Stéphane Lopez, MD, ${ }^{\mathrm{k}}$ Thierry Folliguet, MD, PhD, ${ }^{\mathrm{a}}$ and Mathieu Debauchez, $\mathrm{MD}^{\mathrm{a}}$
}

Objective: We suggest standardizing aortic valve repair using a physiologic approach by associating root remodeling with resuspension of the cusp effective height and external subvalvular aortic ring annuloplasty.

Methods: A total of 187 patients underwent remodeling associated with subvalvular aortic ring annuloplasty (14 centers, 24 surgeons). Three strategies for cusp repair were evaluated: group 1, gross visual estimation (74 patients); group 2, alignment of cusp free edges (62 patients); and group 3, 2-step approach, alignment of the cusp free edges and effective height resuspension (51 patients). The composite outcome was defined as recurrence of aortic insufficiency of grade 2 or greater and/or reoperation.

Results: The operative mortality rate was $3.2 \%(n=6)$. Treatment of a cusp lesion was most frequently performed in group 3 (70.6\% vs $20.3 \%$ in group 1 and $30.6 \%$ in group $2, P<.001)$. Nine patients required reoperation during a follow-up period of 24 months (range, 12-45), 6 patients in group 1 and 3 patients in group 2 . At 1 year, no patients in group 3 presented with composite outcome events compared with $28.1 \%$ in group 1 and $15 \%$ in group $2(P<.001)$. Residual aortic insufficiency and tricuspid anatomy were independent risk factors for the composite outcome in groups 1 and 2. The annulus diameter, the presence of Marfan syndrome, and cusp repair had no effect on aortic insufficiency recurrence or reoperation.

Conclusions: A standardized and physiologic approach to aortic valve repair, considering both the aorta (root remodeling) and the valve (resuspension of the cusp effective height and subvalvular ring annuloplasty) improved the preliminary results and might affect their long-term durability. The ongoing Conservative Aortic Valve Surgery for Aortic Insufficiency and Aneurysm of the Aortic Root (CAVIAAR) trial will compare this strategy to mechanical valve replacement. (J Thorac Cardiovasc Surg 2010;140:S28-35)

Aortic valve-sparing operations are accepted as an alternative to composite aortic valve and root replacement. ${ }^{1,2}$ However, the standardization of root reconstruction and cusp management remains controversial. The 2 original

Department of Cardiac Surgery, ${ }^{\text {a }}$ Institut Mutualiste Montsouris, Paris; Department of Cardiovascular Surgery, ${ }^{\mathrm{b}}$ Foch Hospital, Suresnes; Department of Cardiac Surgery, ${ }^{\mathrm{c}}$ Belledone Clinics, Saint Martin D'heres; Department of Cardiac Surgery, ${ }^{\mathrm{d}}$ Dijon Hospital CHU, Dijon; Department of Cardiac Surgery, ${ }^{\mathrm{e}}$ Michalon Hospital CHU, La Tronche; Department of Cardiac Surgery, ${ }^{f}$ Rouen CHU Hospital, Rouen; Department of Cardiac Surgery, ${ }^{\mathrm{g}}$ Montpellier CHU, Montpellier; Department of Cardiac Surgery, ${ }^{\mathrm{h}}$ Nancy Hospital, Vandœuvre-lès-Nancy; Department of Cardiac Surgery, ${ }^{\mathrm{i}}$ Pitie Salpetriere Hospital, Paris; Department of Cardiac Surgery, Saint Gatien Clinics, Tours; and Department of Cardiac Surgery, ${ }^{\mathrm{k}}$ Institut Arnaud Tzanck, Saint Laurent du Var, France.

Disclosures: Emmanuel Lansac is a consultant for Coroneo. Jean-Paul Bessou reports royalties from Edwards TAVI. Isabelle Di Centa, Ghassan Sleilaty, Eric Arnaud Crozat, Olivier Bouchot, Rachid Hacini, Dominique Blin, Fabien Doguet, Bernard Albat, Roland De Maria, Jean-Pierre Villemot, Eric Portocarrero, Christophe Acar, Didier Chatel, Stéphane Lopez, Thierry Folliguet, and Mathieu Debauchez have nothing to disclose with regard to commercial support.

Received for publication April 29, 2010; revisions received Aug 2, 2010; accepted for publication Aug 5, 2010.

Address for reprints: Emmanuel Lansac, MD, PhD, Department of Cardiovascular Surgery, Institut Mutualiste Montsouris, 42 Boulevard Jourdan, Paris 75014, France (E-mail: emmanuel.lansac@imm.fr).

$0022-5223 / \$ 36.00$

Copyright (C) 2010 by The American Association for Thoracic Surgery doi:10.1016/j.jtcvs.2010.08.004 valve-sparing procedures-remodeling of the aortic root and reimplantation of the aortic valve-focused on root reconstruction to reduce the dilated root diameters and restore proper valve function. ${ }^{3,4}$ The reimplantation technique offers aortic annulus support but withdraws the sinuses of Valsalva and includes the interleaflet triangles within a graft tube, thus impairing root dynamics. ${ }^{5-7}$ In contrast, the remodeling technique provides more physiologic movements of the cusps within 3 reconstructed neosinuses, thus preserving root expansibility through the interleaflet triangles but without addressing annular base dilation. ${ }^{5-8}$ Numerous technical variations have been aimed at preservation of the aortic root dynamics with treatment of the dilated native annulus. ${ }^{9,10}$ This resulted in a lack of standardization and limited their widespread application.

Furthermore, most failures with valve-sparing techniques have resulted from residual cusp prolapse, either as a primary unrecognized lesion or secondary to an induced prolapse after root reconstruction. ${ }^{11-14}$ Despite its more frequent detection intraoperatively, cusp prolapse remains challenging to evaluate and treat.

The present preliminary multicenter report describes a standardized aortic valve repair approach addressing 


\section{Abbreviations and Acronyms \\ AI $=$ aortic insufficiency \\ CAVIAAR $=$ Conservative Aortic Valve surgery \\ for aortic Insufficiency and \\ Aneurysm of the Aortic Root \\ TEE $=$ transesophageal echocardiography}

both the aorta and the valve, associating physiologic reconstruction of the aortic root, according to the remodeling technique, with cusp resuspension and subvalvular external aortic ring annuloplasty. ${ }^{15,16}$ The outcomes of 187 patients who underwent surgery through this technique using 3 different strategies for cusp repair were evaluated.

\section{MATERIALS AND METHODS}

Between May 2003 and December 2009, 187 patients with dystrophic aortic root aneurysms were included in the present study. They all gave informed consent before inclusion. Those with acute aortic dissection were excluded. All patients were assessed preoperatively using transthoracic echocardiography and computed tomography of the chest. The data were collected prospectively. A total of 14 French cardiac centers and 24 surgeons participated in the study. The aortic root reconstruction procedure was standardized for all patients and was performed with the remodeling technique with subvalvular annuloplasty using an external prosthetic ring. ${ }^{15,16}$ Three groups were defined according to the cusp repair strategy: group 1, gross visual estimation (74 patients); group 2, alignment of cusp free edges (62 patients); and group 3, a 2-step approach, alignment of the cusp free edges plus effective height resuspension (51 patients). ${ }^{17,18}$

\section{Surgical Techniques for Root Reconstruction}

All the patients underwent intraoperative transesophageal echocardiography (TEE) to analyze the underlying mechanism of pre- and postrepair aortic insufficiency (AI) and to guide the surgical management of AI. ${ }^{14,19}$ Intact fenestration, a bicuspid valve, and limited calcifications were not contraindications for valve repair.

After resection of the sinuses of Valsalva to within $2 \mathrm{~mm}$ of the aortic annulus, external dissection of the subvalvular plane was performed, below the nadir of insertion of each of the cusps. Next, the native aortic annular base diameter was measured with Hegar dilators, and was the singular criterion for choosing the size of the Valsalva graft used to remodel the aortic root (Gelweave Valsalva, Vascutek Ltd, Renfrewshire, UK). The diameter of the prosthetic external aortic ring was undersized by 1 size relative to the internal aortic annular base diameter (Figure 1, D). Five $\mathrm{U}$ stitches $(2.0$ coated polyester fiber) were placed circumferentially from inside out in the subvalvular plane, below the nadirs of each cusp and at the base of each interleaflet triangle, except for the 1 located between the right and noncoronary sinuses to avoid potential injury to the bundle of His and the membranous septum (Figure 1, $A$ ). The alignment of the cusp free edges was performed at this stage for groups 2 and 3 . Remodeling of the aortic root was standardized by scalloping the Valsalva graft into 3 symmetric neosinuses using the linear demarcations on the bulging part of the graft (tricuspid valve) or into 2 symmetric neosinuses (bicuspid valve). Effective height resuspension was performed at this stage for group 3 . The 5 anchoring $\mathrm{U}$ stitches were then passed through the inner aspect of the prosthetic aortic ring. The ring was seated externally around the remodeled aortic root and tied in the subvalvular position (Figure 1, B). The aortic ring was fashioned from a slice of a Dacron tube graft. The coronary ostia but- tons were connected to the corresponding neosinuses of Valsalva, and the distal anastomosis was performed in the standard fashion (Figure 1,C).

\section{Surgical Techniques for Cusp Repair}

In all the patients, remodeling of the aortic root and subvalvular annuloplasty was completed for all the patients, as described in the previous section. The technique used to identify the cusp prolapse was left to surgeon preference and divided the patients into 3 groups. In group 1, cusp prolapse was defined as a lower level of cusp free edge compared with the adjacent cusps and was assessed by gross visual estimation after root remodeling and subvalvular annuloplasty.

In groups 2 and 3 , alignment of adjacent cusp free edges was performed after placement of the 5 anchoring $U$ stitches but before root remodeling and ring implantation. ${ }^{15,17}$ Any excess length was treated by central plicating stitches to equalize each hemicusp (Figure 2, $A$ and $B$ ) or through a limited resection of the free margin in cases of a bicuspid valve when the excess length was greater than $5 \mathrm{~mm}$.

In group 3, alignment of the cusp free edges was associated with effective height resuspension performed after root remodeling and previous subvalvular ring implantation. It was defined according to Bierbach and colleagues ${ }^{11}$ and Schäfers and colleagues ${ }^{18}$ as the height difference between the central free margin and the lowest point of the aortic insertion line of each cusp. After root reconstruction, commissural traction sutures were placed to measure the effective height of each cusp with a dedicated caliper (Fehling Instruments, Karlstein, Germany) (Figure 2, C). Central plicating stitches were added to the free edge of the culprit leaflet until an effective height of 9 to $10 \mathrm{~mm}$ was obtained.

A follow-up TEE scan was performed after the patient was weaned from cardiopulmonary bypass when the mean aortic pressure was greater than $70 \mathrm{~mm} \mathrm{Hg}$.

The patients were followed up postoperatively using transthoracic echocardiography before hospital discharge, at 6 and 12 months postoperatively, and yearly thereafter. All the patients received prophylactic subcutaneous low-molecular-weight heparin while in-hospital and were discharged with instructions to take antiplatelet agents for 6 weeks. The follow-up data were retrieved from the clinical records and directly from the patients and/or their referring cardiologists, querying for embolic events, bleeding complications, and any valve-related problems.

\section{Statistical Analysis}

The results are expressed as frequencies and percentages for qualitative data. Assumptions of normality were not met, and continuous and ordinal data are expressed as the median with its interquartile range (first quartile to third quartile). The univariate comparison of the 3 groups was done using the $\chi^{2}$ and Kruskal-Wallis statistics, as appropriate. The step-down Sidak algorithm for multiple comparisons was used for correction of the univariate $P$ values.

A multivariate ordinal regression model was used to determine the predictors of worsening or recurring AI at 1 year of follow-up. The AI distribution at 1 year was skewed left, and the negative log-log function was used as a link function between the dependent variable (AI) and the independent variables (group, age, Marfan habitus, bicuspid anatomy, New York Heart Association functional class, preoperative AI, aortic crossclamp time, annular base diameter, associated cardiac procedures, cusp repair, and residual AI). The model's adequacy was assessed using the McFadden pseudo $\mathrm{R} 2$ and the test of parallel lines. Because no failures occurred in group 3, the patients from group 3 were excluded from the multivariate model.

A composite outcome was built and defined as either the recurrence of AI of grade 2 or greater and/or reoperation during follow-up. Survival curves were plotted using the Kaplan-Meier method with AI of grade 2 or greater and the composite outcome as events; the log-rank test was used.

All the tests were 2-sided. All the computations were done using the Statistical Package for Social Sciences, version 13 (SPSS, Inc, Chicago, Ill), statistical software. 


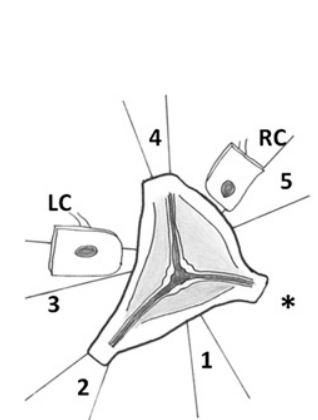

A
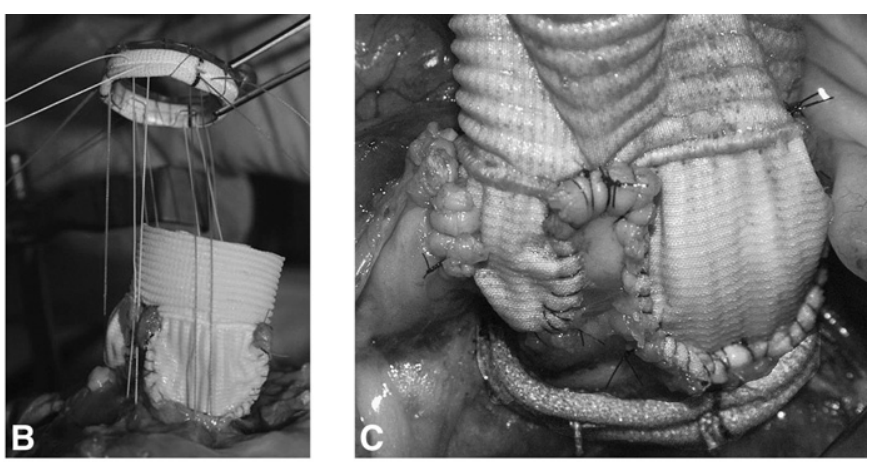

$\varnothing$ Aortic annular base $(\mathrm{mm})$

\begin{tabular}{|l|c|c|c|c|c|}
\hline \multirow{2}{*}{} & \multicolumn{5}{c|}{$\varnothing$ Aortic annular base $(\mathrm{mm})$} \\
\cline { 2 - 7 } & $25-26$ & $27-28$ & $29-30$ & $31-32$ & $33-34$ \\
\hline$\varnothing$ Tube graft & 26 & 28 & 30 & 32 & 34 \\
\hline Ø Subvalvular ring & 23 & 25 & 27 & 29 & 31 \\
\hline
\end{tabular}

FIGURE 1. Standardized steps in remodeling of aortic root associated with an external subvalvular aortic ring annuloplasty. A, Five U stitches are circumferentially placed, inside out, in the subvalvular plane (*bundle of His). B, The ring is pulled around the graft and tied in the subvalvular position. C, Final aspect after coronary ostia reimplantation. D, Criteria for selection of the prosthetic annuloplasty ring size (Extra-Aortic, Coroneo, Inc,)and tube graft size (Gelweave Valsalva). $N C$, noncoronary; $R C$, right coronary; $L C$, left coronary.

\section{RESULTS}

The demographic and operative data for all 3 groups are listed in Table 1. Associated cardiac procedures were performed in 43 cases (coronary bypasses in 18, mitral valve repair in 9, closure of patent foramen ovale in 7, arch replacement in 5, and atrial fibrillation ablation in 4). Prolapse correction was achieved in 70 patients $(37.4 \%)$; it was most frequently detected and treated in group $3(P=.017)$, which corresponded with our more recent practice. The choice of the technique of cusp repair was left to the surgeon and evolved with time toward central plication of the free margins. The aortic ring significantly reduced the native aortic annular base diameter $(-24.9 \%)$, with no significant increase in the transvalvular gradient (mean $5.2 \pm 2.3 \mathrm{~mm} \mathrm{Hg}$ ).

Intraoperative residual AI of grade 2 or greater was less frequently encountered in group $3(n=1)$ than in groups 1 $(\mathrm{n}=6)$ and $2(\mathrm{n}=8)$; the difference was not statistically significant. A second cardiopulmonary bypass run was decided during the same operation in 6 patients, and residual cusp prolapse was found in all 6 cases. A conversion to mechanical valve replacement was required in 2 of these patients (group 1), and the valve was successfully re-repaired in 4 (groups 2 and 3 ).

The 30-day mortality rate was $3.2 \%$ (6 patients, 2 in each group). The 6 patients had died of mesenteric ischemia with multiple organ failure $(n=5)$ or massive pulmonary embo$\operatorname{lism}(\mathrm{n}=1)$.

Two patients died after a prolonged 3- and 6-month hospital stay, 1 of stroke due to paradoxical embolism through a patent foramen ovale and 1 of severe pneumonia.

The valve-related complications at 30 days included 3 reversible ischemic neurologic deficits. Also, 9 patients
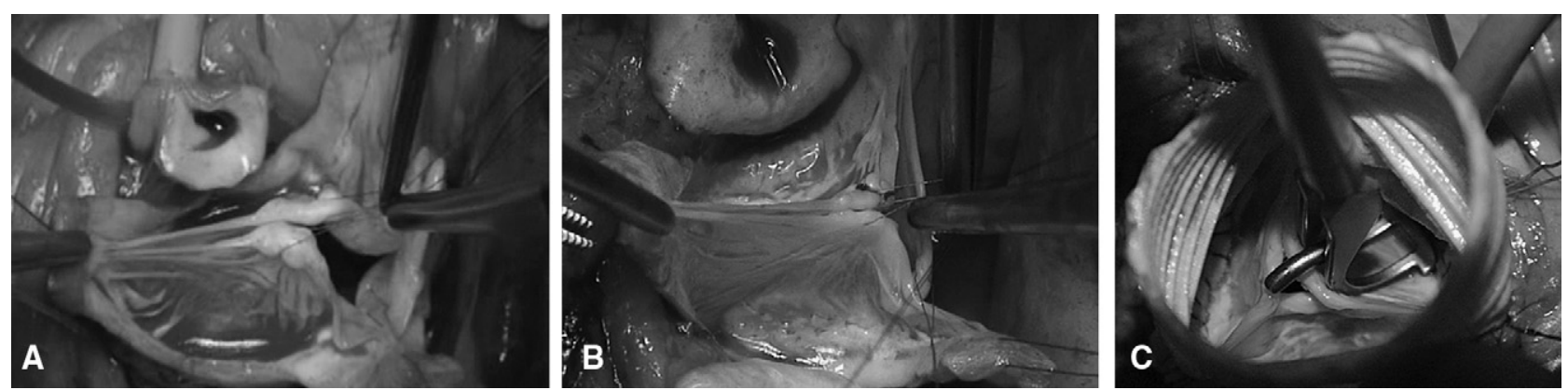

FIGURE 2. Standardized steps for cusp repair. A and B, Alignment of adjacent cusp free edges evaluates the excess length, which is corrected by plicating central stitches. C, Cusp effective height is measured using a dedicated cusp caliper (Fehling Instruments) after root remodeling and previous ring implantation. Residual or induced cusp prolapse was corrected by additional central plicating stitches. 
TABLE 1. Baseline characteristics for 3 groups studied

\begin{tabular}{|c|c|c|c|c|c|}
\hline & $\begin{array}{c}\text { Group } 1 \text { (gross visual } \\
\text { estimation) }\end{array}$ & $\begin{array}{l}\text { Group } 2 \text { (free edge } \\
\text { alignment) }\end{array}$ & $\begin{array}{c}\text { Group } 3 \text { (2-step: free edge } \\
\text { alignment, effective } \\
\text { height resuspension) }\end{array}$ & $P$ value & $\begin{array}{l}\text { Corrected } \\
P \text { value* }\end{array}$ \\
\hline Patients (n) & 74 & 62 & 51 & & \\
\hline Bicuspid aortic valve & $10(13.5)$ & $11(17.7)$ & $19(37.3)$ & .003 & .041 \\
\hline Marfan syndrome & $19(25.7)$ & $5(8.1)$ & $3(5.9)$ & .002 & .030 \\
\hline Age (y) & $51(40-61)$ & $61(50-68)$ & $61(47-69)$ & .004 & .051 \\
\hline \multicolumn{6}{|l|}{ NYHA class } \\
\hline I & 36 & 35 & 39 & & \\
\hline II & 33 & 18 & 7 & & \\
\hline III & 5 & 8 & 4 & & \\
\hline IV & - & 1 & 1 & .007 & .068 \\
\hline Preoperative aortic annular base $\varnothing(\mathrm{mm})$ & $28(26-28)$ & $26(25-28)$ & $28(26-29)$ & .006 & .064 \\
\hline Aneurysm diameter (mm) & $54(50-59)$ & $53(50-56)$ & $51(50-53)$ & .002 & .032 \\
\hline \multicolumn{6}{|l|}{ Preoperative AI grade } \\
\hline 0 & 15 & 8 & 10 & & \\
\hline 1 & 6 & 12 & 9 & & \\
\hline 2 & 19 & 19 & 13 & & \\
\hline 3 & 27 & 20 & 13 & & \\
\hline 4 & 7 & 3 & 6 & .448 & .949 \\
\hline Cusp repair & $15(20.3)$ & $19(30.6)$ & $36(70.6)$ & $<.001$ & .017 \\
\hline Plicating stitches & 5 & 15 & 27 & & \\
\hline Cusp resection & 6 & 4 & 6 & & \\
\hline Running suture & 5 & 6 & 2 & & \\
\hline Cusp decalcification & 1 & 2 & 3 & & \\
\hline Pericardial patch & 1 & - & - & & \\
\hline Direct suture of cusp defect & 1 & - & - & & \\
\hline \multicolumn{6}{|l|}{ Second CPB run } \\
\hline Coronary bypass & - & - & 2 & & \\
\hline Hemostasis on graft suture line & - & 1 & - & & \\
\hline Aortic crossclamping time (min) & $127(109-145)$ & $130(116-155)$ & $135(117-166)$ & .068 & .469 \\
\hline With cusp repair $\dagger$ & $133(127-145)$ & $153(138-166)$ & $135(120-166)$ & .286 & .905 \\
\hline Without cusp repair $\dagger$ & $117(104-137)$ & $117(112-126)$ & $115(110-117)$ & .796 & .998 \\
\hline Tube graft diameter (mm) & $28(26-28)$ & $26(26-28)$ & $28(28-29)$ & $<.001$ & .018 \\
\hline Aortic ring diameter (mm) & $28(26-28)$ & $28(25-28)$ & $27(25-27)$ & .005 & .058 \\
\hline AI grade $\geq 2$ on intraoperative TEE & $6(8.1)$ & $8(12.9)$ & $1(1.9)$ & .071 & .445 \\
\hline Re-repair for residual AI & - & 3 & 1 & & \\
\hline Conversion for valve replacement & 2 & - & - & & \\
\hline Postoperative aortic annular base $\varnothing(\mathrm{mm})$ & $20(19-21)$ & $20(19-21)$ & $20(19-21)$ & .886 & .987 \\
\hline Operative mortality & $2(2.7)$ & $2(3.2)$ & $2(3.9)$ & .931 & .931 \\
\hline Follow-up (mo) & $54(38-67)$ & $24(19-31)$ & $10(4-14)$ & $<.001$ & .019 \\
\hline Follow-up (pt-y) & 297.8 & 119.3 & 38.8 & & \\
\hline \multicolumn{6}{|l|}{ 1-y Outcomes } \\
\hline Patients (n) & 64 & 60 & 47 & & \\
\hline AI grade $\geq 2$ & $16(25.0)$ & $9(15.0)$ & $0(0.0)$ & .001 & \\
\hline Reoperation rate & $2(3.1)$ & $1(1.7)$ & $0(0.0)$ & .463 & \\
\hline Composite outcome & $18(28.1)$ & $9(15.0)$ & $0(0.0)$ & $<.001$ & \\
\hline
\end{tabular}

Qualitative data are presented as number (\%). Continuous and ordinal data are presented as median (first to third quartile). *Correction of $P$ value using step-down Sidak algorithm for multiple comparisons. †Patients with associated cardiac procedure were excluded. Composite outcome defined as recurrence of AI grade $\geq 2$ and/or reoperation during follow-up. NYHA, New York Heart Association; $A I$, aortic insufficiency; $\emptyset$, diameter; $T E E$, transesophageal echocardiography; $C P B$, cardiopulmonary bypass.

$(4.8 \%)$ required mediastinal re-exploration for bleeding. Pericardial effusions with cardiac tamponade required drainage in 8 cases $(4.3 \%)$. Finally, 6 patients developed heart block requiring a permanent pacemaker. Of these 6 patients, 3 had bicuspid valves; the other 3 had undergone surgery early during our experience and their subvalvular annuloplasty ring had been anchored with 6 stitches. Hence, the sixth stitch, which was located below the commissure at the base of the interleaflet triangle between the noncoronary, and the right coronary sinus of Valsalva had been omitted to avoid potential damage to the bundle of His and the membranous septum. 
Follow-up was complete for $99.5 \%$ of the patients, totaling 456 patient-years, with a median of 24 months (range, 12-45). Three sudden unexplained deaths occurred at 2,5 , and 8 months postoperatively. One patient presented with a transient ischemic attack at 2 months postoperatively. No hemorrhagic events occurred. At the most recent follow-up of 166 survivors without reoperation, 156 (94\%) had New York Heart Association functional class I and $10(6 \%)$ class II.

Nine patients underwent reoperation for aortic valve replacement: 6 from group 1 at $3,5,27,34,46$, and 50 months after the initial repair and 3 from group 2 at 12, 22, and 36 months after the initial repair. No patients in group 3 showed deterioration of the repair. Of these 9 reoperated patients, 5 had undergone cusp repair during the initial operation with running sutures in 4 (cusp prolapse in 1 patient and fenestrations rupture in 3 ) and an autologous pericardial patch in 1 for aortic endocarditis and a mitral-aortic abscess. The remaining 4 patients had not undergone cusp repair during the initial operation. Of these 4 patients, 2 had had Marfan syndrome and 2 had had preoperative AI grade 3 or greater. Of the 9 reoperated patients, 5 had a residual eccentric AI greater than grade 1 on TEE during the initial operation, with no additional repair or valve replacement.

The operative findings at reoperation were endocarditis in 2 patients that had developed at 36 and 50 months postoperatively (1 patient had had primary endocarditis at the first operation). Cusp prolapse was the cause for recurrent $\mathrm{AI}$ in the other 7 patients, without any annular base dilation. Prolapse was associated with restrictive cusps in 2 patients, both with Marfan syndrome and cusp perforation in 1 . All patients survived reoperation.

Of the 9 patients who were discharged with AI of grade 2 or greater, the AI remained stable, except for in 2 patients in whom the AI increased to grade 3 . These 2 patients have been followed closely, because they have remained asymptomatic with a normal left ventricular function at the last echocardiographic examination (at 6 and 79 months of follow-up). In all patients, the aortic annular base reduction remained stable during follow-up, with low mean systolic gradient (7.5 $\pm 4 \mathrm{~mm} \mathrm{Hg}$; range, 1.1-16).

On crude analysis, the rate of AI of grade 2 or greater at 1 year of follow-up drastically decreased from $25 \%$ in group 1 to $15 \%$ in group 2 to a null value in group $3(P=.001)$ (Table 1). For groups 1 and 2, after adjustment for the other covariates, AI at 1 year of follow-up was more likely to recur or worsen in patients with residual postoperative AI, those with tricuspid anatomy, those in group 1, and those with preoperative AI greater than grade 2, in order of decreased importance, as listed in Table 2.

Likewise, the 1-year composite outcome (reoperation and/or AI of grade 2 or greater) decreased drastically from $28.1 \%$ in group 1 to $15 \%$ in group 2 to a null value in group $3(P<.001)($ Table 1$)$.
TABLE 2. Independent predictors for increase or recurrence of AI at 1 year

\begin{tabular}{lcccc}
\hline \multicolumn{1}{c}{ Parameter } & Estimate $^{*}$ & Standard error & $\mathbf{9 5} \%$ CI & $\boldsymbol{P}$ value \\
\hline Residual AI & 1.040 & 0.233 & $0.582-1.497$ & .001 \\
Tricuspid AV & 1.008 & 0.433 & $0.160-1.856$ & .020 \\
Group 1 & 0.551 & 0.293 & -0.024 to 1.126 & .060 \\
Preoperative AI & 0.266 & 0.135 & $0.001-0.530$ & .049 \\
\hline
\end{tabular}

*Coefficients of multivariate ordinal regression model using negative log-log as a link function between dependent variable (AI) and independent variables. Only significant or near significant factors shown. The absolute value of the estimate reflects the importance of its influence on the dependent variable. The model's McFadden pseudo $\mathrm{R} 2=0.126$. Patients from group 3 were excluded from analysis because no failures occurred. AI, Aortic insufficiency; $A V$, aortic valve; $C I$, confidence interval around estimate.

The freedom from AI of grade 2 or greater and freedom from the composite outcome as a function of group and aortic valve anatomy are plotted in Figure 3.

The preoperative annulus diameter, the presence of Marfan syndrome, and the additional cusp repair had no negative effect on AI recurrence or the need for reoperation.

\section{DISCUSSION}

The experience of the past decades has made mitral valve repair the treatment of choice for mitral insufficiencies. Its spread was made possible by a standardization of technique, associating leaflet repair with prosthetic ring annuloplasty, to ensure reliable and reproducible results. ${ }^{20,21}$ The superiority of mitral repair compared with mechanical replacement, as well as a better knowledge of the functional anatomy of the aortic root, have greatly influenced the progress in aortic valve-sparing procedures. Multiple techniques have been tried to meet the complex interplay of the aortic valve and root function to improve the durability of the repair. Remodeling of the aortic root is an appealing procedure; because it allows for physiologic reconstruction of the aortic root with neosinuses of Valsalva and preservation of root expansibility through the interleaflet triangles. It was favored in our early experience of valve-sparing procedures. However, we experienced a high rate of intraoperative failure, consistent with other series describing recurrence of significant aortic regurgitation in up to $30 \%$ of patients. $3,8,13,16$ The risk factor for early and late failure is a dilated native aortic annulus (diameter $\geq 25 \mathrm{~mm}$ ). ${ }^{8,13,16}$ Although this dilated aortic annular base can be treated through the proximal suture of the reimplantation technique, the root dynamics will be impaired by the inclusion of the valve within the graft. ${ }^{5-7}$ Therefore, we suggested combining the advantages of both the remodeling and the reimplantation technique by adding external subvalvular prosthetic ring annuloplasty to the physiologic remodeling of the aortic root. ${ }^{15,16}$ With this standardized technique, reclamping for residual $\mathrm{AI}$ of grade 2 or greater decreased from $30 \%$ when using isolated remodeling to $3.2 \%$ in the present study. ${ }^{16}$ 

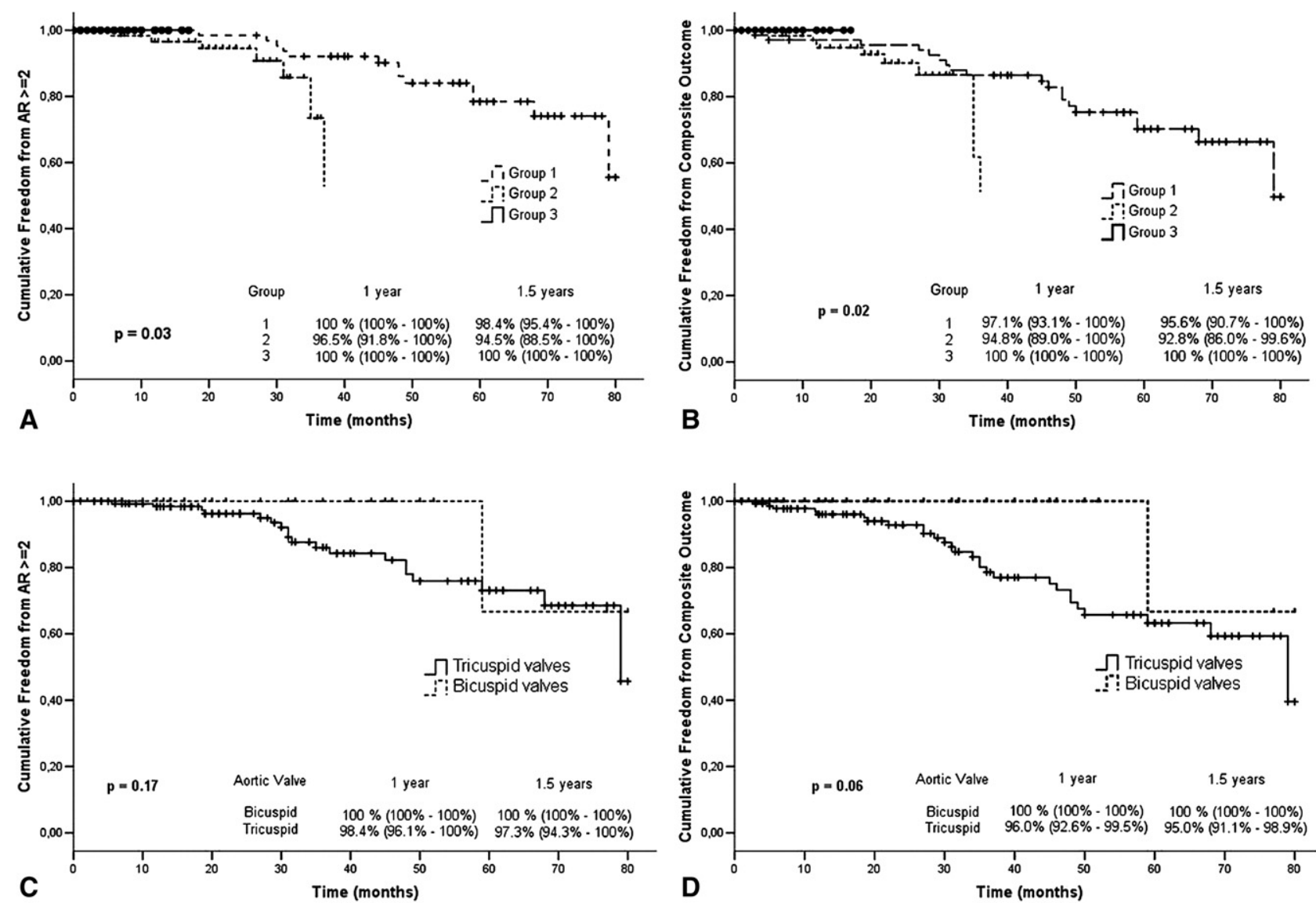

FIGURE 3. A, Freedom from AI grade 2 or greater in 3 groups $(P=.03)$. B, Freedom from composite outcome in 3 groups $(P=.02)$. C, Freedom from AI grade 2 or greater between bicuspid and tricuspid aortic valves $(P=.17)$. D, Freedom from composite outcome for bicuspid and tricuspid valves $(P=.06)$.

Although restoration of the root geometry is an important prerequisite for a successful valve-sparing procedure, preventing recurrence of AI remains a challenge. ${ }^{14,22,23}$ Consistent with other investigators, the main cause of reoperation in the present study was cusp prolapse. Recent series have reported an ever-increasing rate of cusp repair and have advocated the combination of aggressive management of cusp lesions with root reconstruction to improve the valve-sparing results. ${ }^{22,24}$ Echocardiographic and intraoperative assessment of cusp prolapse can be difficult. In our multicenter experience, cusp repair was managed using 3 different approaches. In group 1, cusp prolapse was defined as a lower height of a free margin relative to the adjacent cusp margins, resulting in a $20.3 \%$ rate of cusp repair. This subjective evaluation, which corresponded to our early experience, was associated with an $8.1 \%$ rate of intraoperative residual $\mathrm{AI}$ of grade 2 or greater and a $28.1 \%$ rate of events of the composite outcome (recurrence of AI grade 2 or greater and/or reoperation) at 1 year $(P<.001$ compared with group 3$)$. It was also an independent predictor of an increase or recurrence of $\mathrm{AI}$ at 1 year of follow-up.

Isolated alignment of the cusp free edges was performed according to Boodhwani and colleagues ${ }^{17}$ in group 2. It led to the diagnosis of cusp prolapse more frequently, with a slight improvement in the results (a rate of $15 \%$ events of the composite outcome at 1 year). In group 3, the approach to valve repair was standardized into a 2 -step procedure. The first step was performed before root remodeling to align the cusp free edges and correct any excess length. The second step was performed after suturing of the graft but before ring implantation, using a cusp caliper to obtain symmetric cusp resuspension with an effective height of 8 to $10 \mathrm{~mm}$ or greater, as described by Schäfers and colleagues. ${ }^{18}$ The effective height resuspension dramatically increased the rate of cusp repair $(70.6 \%)$ and improved the operative and early results for group 3, with no events of the composite outcome reported at 1 year. This 2-step approach allowed correction of any residual or induced symmetric prolapse after reduction of the sinotubular junction provided by the remodeling procedure. Soncini and colleagues, ${ }^{5}$ using finite element analysis, showed that the noduli of Arantius were lowered toward the valve orifice during valve closure after reimplantation $(3.8 \mathrm{~mm})$ and remodeling $(3.3 \mathrm{~mm})$. Subvalvular annuloplasty through an aortic ring or proximal suture of a reimplantation tube graft will partially compensate for the induced symmetric prolapse by 
increasing the coaptation height. However, in the absence of cusp resuspension, the coaptation level could remain too low (at the level of the aortic annular plane or below). This can induce a billowing aspect of the cusps, with a progressive lowering of the coaptation level and height $(<4 \mathrm{~mm})$, which have been described as risk factors for reoperation. ${ }^{14}$

The multicenter design of the present study enhanced the reproducibility of this standardized management of both the aorta and the valve, because only 1 patient presented with an intraoperative residual AI grade 2 or greater in group 3. Residual AI was identified as a risk factor for AI recurrence or reoperation in groups 1 and 2. Consistent with the other teams, our more recent practice (group 3) evolved toward strict intraoperative TEE criteria for good results, such that any eccentric jet or aortic regurgitation greater than grade 1 prompted additional correction. ${ }^{14}$

The preoperative annulus diameter, the presence of Marfan syndrome, and cusp repair were not risk factors for AI recurrence or reoperation. Repair of bicuspid valves showed better results than tricuspid valve anatomy. This could be partly explained by the greater rate of cusp repair in patients with bicuspid valves ( $72 \%$ of patients vs $28 \%$ of patients for tricuspid valves). Apart from the high rate of cusp repair, the better results in group 3 also could reflect the completion of a learning curve or other confounding factors, because these patients underwent surgery later in the study period.

The results of the present study suggest that a standardized procedure, associating the resuspension of the effective cusp height with complete circumferential annuloplasty, could improve the stability of aortic valve repair. To address the need for a dedicated aortic annuloplasty device to facilitate technical standardization, we designed a new expansible aortic ring to achieve complete and calibrated annuloplasty in diastole, while maintaining the systolic expansibility of the aortic root. ${ }^{25}$ As such, the cusp coaptation height is increased, reducing stress on the cusps and protecting the repair.

\section{CONCLUSIONS}

Aortic valve-sparing procedures were focused initially on restoring the root dimensions. However, a current trend exists toward moving from valve sparing to valve repair to also restore the cusp effective height. A standardized and physiologic approach to aortic valve repair, addressing both the aorta (root remodeling) and the valve (resuspension of the cusp effective height and subvalvular ring annuloplasty), seems to improve the preliminary results and could affect their long-term durability. The ongoing multicenter Conservative Aortic Valve surgery for aortic Insufficiency and Aneurysm of the Aortic Root (CAVIAAR) trial is currently investigating the role of this procedure using the expansible aortic ring compared with the Bentall procedure.

\section{References}

1. Hiratzka LF, Bakris GL, Beckman JA, Bersin RM, Carr VF, Casey DE Jr, et al. ACCF/AHA/AATS/ACR/ASA/SCA/SCAI/SIR/STS/SVM guidelines for the diagnosis and management of patients with thoracic aortic disease: A report of the American College of Cardiology Foundation/American Heart Association Task Force on Practice Guidelines, American Association for Thoracic Surgery, American College of Radiology, American Stroke Association, Society of Cardiovascular Anesthesiologists, Society for Cardiovascular Angiography and Interventions, Society of Interventional Radiology, Society of Thoracic Surgeons, and Society for Vascular Medicine. Circulation. 2010; 121:e266-369.

2. Volguina IV, Miller DC, LeMaire SA, Palmero LC, Wang XL, Connolly HM, et al. Valve-sparing and valve-replacing techniques for aortic root replacement in patients with Marfan syndrome: Analysis of early outcome. J Thorac Cardiovasc Surg. 2009; 137:1124-32.

3. Yacoub MH, Gehle P, Chandrasekaran V, Birks EJ, Child A, Radley-Smith R. Late results of a valve sparing operation in patients with aneuryms of the ascending aorta and root. J Thorac Cardiovasc Surg. 1998;115:1080-90.

4. David TE, Armstrong S, Maganti M, Colman J, Bradley TJ. Long-term results of aortic valve-sparing operations in patients with Marfan syndrome. J Thorac Cardiovasc Surg. 2009;138:807-1050.

5. Soncini M, Votta E, Zinicchino S, Burrone V, Mangini A, Lemma M, et al. Aortic root performance after valve sparing procedure: A comparative finite element analysis. Med Eng Phys. 2009;31:234-43.

6. De Paulis R, De Matteis GM, Nardi P, Scaffa R, Buratta MM, Chiariello L. Opening and closing characteristics of the aortic valve after valve-sparing procedures using a new aortic root conduit. Ann Thorac Surg. 2001;72:487-94.

7. Fries R, Graeter T, Aicher D, Reul H, Schmitz C, Böhm M, et al. In vitro comparison of aortic valve movement after valve-preserving aortic replacement. J Thorac Cardiovasc Surg. 2006;132:32-7.

8. Luciani GB, Casali G, Tomezzoli A, Mazzucco A. Recurrence of aortic insufficiency after aortic root remodeling with valve preservation. Ann Thorac Surg. 1999;67:1849-52.

9. Svensson LG, Cooper M, Batizy LH, Nowicki ER. Simplified David reimplantation with reduction of annular size and creation of artificial sinuses. Ann Thorac Surg. 2010;89:1443-7.

10. Bakhtiary F, Monsefi N, Trendafilow M, Wittlinger T, Doss M, Moritz A. Modification of the David procedure for reconstruction of incompetent bicuspid aortic valves. Ann Thorac Surg. 2009;88:2047-9.

11. Bierbach BO, Aicher D, Issa OA, Bomberg H, Gräber S, Glombitza P, et al. Aortic root and cusp configuration determine aortic valve function. Eur J Cardiothorac Surg. Epub 2010 Mar 8.

12. Aicher D, Fries R, Rodionycheva S, Schmidt K, Langer F, Schäfers HJ. Aortic valve repair leads to a low incidence of valve-related complications. Eur J Cardiothorac Surg. 2010;37:127-32.

13. Hanke T, Charitos EI, Stierle U, Robinson D, Gorski A, Sievers HH, et al. Factors associated with the development of aortic valve regurgitation over time after two different techniques of valve-sparing aortic root surgery. $J$ Thorac Cardiovasc Surg. 2009; 137:314-9.

14. le Polain de Waroux JB, Pouleur AC, Robert A, Pasquet A, Gerber BL, et al. Mechanisms of recurrent aortic regurgitation after aortic valve repair: Predictive value of intraoperative transesophageal echocardiography. JACC Cardiovasc Imaging. 2009;2:931-9.

15. Lansac E, Di Centa I, Sleilaty G, Bouchot O, Arnaud Crozat E, Blin D, Acar C, et al. An aortic ring to standardise aortic valve repair: Preliminary results of a prospective multicentric cohort of 144 patients. Eur J Cardiothorac Surg. Epub 2010 Mar 6.

16. Lansac E, Di Centa I, Bonnet N, Leprince P, Jault F, Rama A, Acar C, et al. Aortic prosthetic ring annuloplasty: A useful adjunct to a standardized aortic valvesparing procedure? Eur J Cardiothorac Surg. 2006;29:537-44.

17. Boodhwani M, de Kerchove L, Glineur D, El Khoury G. A simple method for the quantification and correction of aortic cusp prolapse by means of free margin plication. J Thorac Cardiovasc Surg. 2010;139:1075-7.

18. Schäfers HJ, Bierbach B, Aicher D. A new approach to the assessment of aortic cusp geometry. J Thorac Cardiovasc Surg. 2006;132:436-8.

19. Lansac E, Di Centa I, Raoux F, Al Attar N, Acar C, Joudinaud T, et al. A lesional classification to standardize surgical management of aortic insufficiency towards 
valve repair. Eur J CardioThorac Surg. 2008;33:872-8.

20. Duran CG, Ubago JL. Clinical and hemodynamic performance of a totally flexible prosthetic ring for atrioventricular valve reconstruction. Ann Thorac Surg. 1976;22:458-63.

21. Carpentier A. Cardiac valve surgery-the "French correction" J Thorac Cardiovasc Surg. 1983;86:323-37.

22. Aicher D, Langer F, Adam O, Tscholl D, Lausberg H, Schäfers HJ. Cusp repair in aortic valve reconstruction: Does the technique affect stability? J Thorac Cardiovasc Surg. 2007;134:1533-8.
23. de Kerchove L, Boodhwani M, Glineur D, Poncelet A, Verhelst R, Astarci P, et al. Effects of preoperative aortic insufficiency on outcome after aortic valve-sparing surgery. Circulation. 2009;120:S120-6.

24. de Kerchove L, Boodhwani M, Glineur D, Poncelet A, Rubay J, Watremez C, et al. Cusp prolapse repair in trileaflet aortic valves: Free margin plication and free margin resuspension techniques. Ann Thorac Surg. 2009;88:455-61.

25. Lansac E, Di Centa I, Raoux F, Bulman-Fleming N, Ranga A, Abed A, et al. An expansible aortic ring for a physiological approach to conservative aortic valve surgery. J Thorac Cardiovasc Surg. 2009;138:718-24. 